\title{
Association of genetic variants with chronic kidney disease in individuals with different lipid profiles
}

\author{
TETSURO YOSHIDA ${ }^{1}$, KIMIHIKO KATO ${ }^{2}$, KIYOSHI YOKOI ${ }^{2}$, MITSUTOSHI OGURI ${ }^{3}$, \\ SACHIRO WATANABE ${ }^{4}$, NORIFUMI METOKI ${ }^{5}$, HIDEMI YOSHIDA $^{6}$, KEI SATOH $^{6}$, \\ YUKITOSHI AOYAGI $^{7}$, YUTAKA NISHIGAKI $^{7}$, YOSHINORI NOZAWA $^{8}$ and YOSHIJI YAMADA ${ }^{9}$
}

\begin{abstract}
${ }^{1}$ Department of Cardiovascular Medicine, Inabe General Hospital, Inabe; ${ }^{2}$ Department of Cardiovascular Medicine, Gifu Prefectural Tajimi Hospital, Tajimi; ${ }^{3}$ Department of Cardiology, Japanese Red Cross Nagoya First Hospital, Nagoya; ${ }^{4}$ Department of Cardiology, Gifu Prefectural General Medical Center, Gifu; ${ }^{5}$ Department of Internal Medicine, Hirosaki Stroke Center, Hirosaki; ${ }^{6}$ Department of Vascular Biology, Institute of Brain Science, Hirosaki University Graduate School of Medicine, Hirosaki; ${ }^{7}$ Department of Genomics for Longevity, Tokyo Metropolitan Institute of Gerontology, Tokyo; ${ }^{8}$ Gifu International Institute of Biotechnology, Kakamigahara; ${ }^{9}$ Department of Human Functional Genomics, Life Science Research Center, Mie University, Tsu, Japan
\end{abstract}

Received January 13, 2009; Accepted March 3, 2009

DOI: $10.3892 /$ ijmm_00000226

\begin{abstract}
The purpose of the present study was to identify genetic variants that confer susceptibility to chronic kidney disease (CKD) in individuals with low or high serum concentrations of triglycerides (TG), high-density lipoprotein (HDL)-cholesterol, or low-density lipoprotein (LDL)cholesterol, thereby contributing to the personalized prevention of CKD in such individuals. The study population comprised 5944 Japanese individuals, including 1706 subjects with CKD [estimated glomerular filtration rate (eGFR) $<60 \mathrm{ml} / \mathrm{min} / 1.73 \mathrm{~m}^{2}$ ] and 4238 controls (eGFR $\geq 60 \mathrm{ml} /$ $\min / 1.73 \mathrm{~m}^{2}$ ). The genotypes for 296 polymorphisms of 202 candidate genes were determined. The Chi-square test, multivariable logistic regression analysis with adjustment for covariates, and a stepwise forward selection procedure revealed that seven different polymorphisms were significantly $(\mathrm{P}<0.005)$ associated with the prevalence of CKD in individuals with low or high serum concentrations of TG or HDL- or LDL-cholesterol: the $\mathrm{A} \rightarrow \mathrm{G}$ (Glu23Lys) polymorphism of $K C N J 11$ and the $125592 \mathrm{C} \rightarrow \mathrm{A}$ (Thr431Asn) polymorphism of ROCK2 in individuals with low serum TG; the $734 \mathrm{C} \rightarrow \mathrm{T}$ (Thr254Ile) polymorphism of ACAT2 and the $\mathrm{C} \rightarrow \mathrm{G}$ (Gln27Glu) polymorphism of $A D R B 2$ in individuals with high serum TG; the $-1607 / 1 \mathrm{G} \rightarrow 2 \mathrm{G}$ polymorphism of $M M P 1$
\end{abstract}

Correspondence to: Dr Yoshiji Yamada, Department of Human Functional Genomics, Life Science Research Center, Mie University, 1577 Kurima-machiya, Tsu, Mie 514-8507, Japan E-mail: yamada@gene.mie-u.ac.jp

Key words: genetics, polymorphism, chronic kidney disease, end-stage renal disease, lipid profile, triglyceride, high-density lipoprotein cholesterol, low-density lipoprotein cholesterol in individuals with low serum HDL-cholesterol; the $\mathrm{G} \rightarrow \mathrm{A}$ (Val158Met) polymorphism of COMT in individuals with low serum LDL-cholesterol; the $584 \mathrm{G} \rightarrow \mathrm{A}$ (Gln192Arg) polymorphism of $P O N 1$ in individuals with high serum LDLcholesterol. No polymorphism was associated with CKD in individuals with high serum HDL-cholesterol. These results suggest that polymorphisms associated with CKD may differ among individuals with different lipid profiles. Stratification of subjects according to lipid profiles may thus be important for personalized prevention of CKD based on genetic information.

\section{Introduction}

Chronic kidney disease (CKD) has been recognized as a global public health problem; individuals with CKD are at an increased risk not only for end-stage renal disease (ESRD), but also for a poor cardiovascular outcome and premature death $(1,2)$. CKD is a multifactorial disorder that is thought to result from an interaction between genetic background and environmental factors. Principal and treatable risk factors for CKD include diabetes mellitus (3), glomerular nephritis (4), hypertension $(5,6)$, and hyperlipidemia or dyslipidemia $(7,8)$. However, the effect of lipid profiles on the development of CKD is controversial given that there are no large studies proving the effect of lipid reduction on the progression of renal disease (9). Disease prevention is an important strategy for reducing the overall burden of CKD and ESRD, and the identification of markers for disease risk is a key both for risk prediction and for potential intervention to reduce the chance of future cardiovascular events (10). It is thus important to identify markers that confer susceptibility to CKD in individuals with different lipid profiles independently.

Although genetic linkage analyses $(11,12)$ and association studies $(13,14)$ have implicated several loci and candidate genes in predisposition to $\mathrm{CKD}$, the genes that contribute to 
genetic susceptibility to CKD remain largely unknown. In addition, given the ethnic differences in lifestyle and environmental factors as well as in genetic background, it is important to examine genetic polymorphisms related to CKD in each ethnic group. We hypothesized that the association of gene polymorphisms with CKD might be influenced by baseline lipid profiles. Here, we performed an association study of 296 polymorphisms of 202 candidate genes and CKD in 5944 Japanese individuals with low or high serum concentrations of triglycerides (TG), high-density lipoprotein (HDL)cholesterol, or low-density lipoprotein (LDL)-cholesterol. The purpose of the present study was to identify genetic variants that confer susceptibility to CKD in individuals with different lipid profiles independently and thereby to assess the genetic risk of CKD in such individuals separately.

\section{Materials and methods}

Study population. The study population comprised 5944 unrelated Japanese individuals who either visited outpatient clinics of or were admitted to one of the participating hospitals (Gifu Prefectural General Medical Center and Gifu Prefectural Tajimi Hospital in Gifu Prefecture, Japan; and Hirosaki University Hospital, Reimeikyo Rehabilitation Hospital, and Hirosaki Stroke Center in Aomori Prefecture, Japan) between October 2002 and March 2008 because of various symptoms or for an annual health checkup, or who were recruited to a population-based prospective cohort study of aging and agerelated diseases in Gunma Prefecture and Tokyo, Japan.

The glomerular filtration rate was estimated with the use of the simplified prediction equation derived from the modified version of that described in the Modification of Diet in Renal Disease (MDRD) Study as proposed by the Japanese Society of Nephrology (15): eGFR (ml min-1 $\left.1.73 \mathrm{~m}^{-2}\right)=194 \times$ [age (years) $]^{-0.287} \times$ [serum creatinine $\left.(\mathrm{mg} / \mathrm{dl})\right]^{-1.094} \times[0.739$ if female]. The National Kidney Foundation - Kidney Disease Outcomes Quality Initiative guidelines recommend a diagnosis of CKD if eGFR is $<60 \mathrm{ml} \mathrm{min}^{-1} 1.73 \mathrm{~m}^{-2}$ (10). Nonlinear relations between GFR and the risk of adverse events such as death, cardiovascular events, and hospitalization have been demonstrated, with an increased risk being associated with an eGFR of $<60 \mathrm{ml} \mathrm{min}^{-1} 1.73 \mathrm{~m}^{-2}$ (16). We thus adopted the criterion of an eGFR of $<60 \mathrm{ml} \mathrm{min}^{-1} 1.73 \mathrm{~m}^{-2}$ for diagnosis of CKD in the present study. On the basis of this criterion, 1706 subjects were diagnosed with CKD. The control subjects comprised 4238 individuals whose eGFR was $\geq 60 \mathrm{ml} \mathrm{min}^{-1}$ $1.73 \mathrm{~m}^{-2}$. The control subjects were recruited from communitydwelling healthy individuals or from patients visiting outpatient clinics regularly for treatment of various common diseases. Subjects with CKD and controls thus either had or did not have conventional risk factors for CKD, including hypertension (systolic blood pressure of $\geq 140 \mathrm{mmHg}$ or diastolic blood pressure of $\geq 90 \mathrm{mmHg}$, or both, or taking antihypertensive medication), or diabetes mellitus (fasting blood glucose of $\geq 6.93 \mathrm{mmol} / \mathrm{l}$ or hemoglobin $\mathrm{A}_{\mathrm{lc}}$ of $\geq 6.5 \%$, or both, or taking antidiabetes medication). Among the total study population, 3946 and 1998 individuals had low $(<1.70 \mathrm{mmol} / \mathrm{l})$ or high $(\geq 1.70 \mathrm{mmol} / \mathrm{l})$ serum concentrations of TG, respectively, and 1023 and 4921 individuals had low $(<1.03 \mathrm{mmol} / \mathrm{l})$ or high $(\geq 1.03 \mathrm{mmol} / \mathrm{l})$ serum concentrations of HDL-cholesterol, respectively. The values for LDLcholesterol were calculated by the Friedewald formula: serum concentration of LDL-cholesterol $=$ (serum concentration of total cholesterol) - (serum concentration of HDL-cholesterol) - $[0.2 \times$ (serum concentration of TG)]. Among the total study population, 4535 and 1409 individuals had low $(<3.63 \mathrm{mmol} / \mathrm{l})$ or high $(\geq 3.63 \mathrm{mmol} / \mathrm{l})$ serum concentrations of LDLcholesterol, respectively.

The study protocol complied with the Declaration of Helsinki and was approved by the Committees on the Ethics of Human Research of Mie University Graduate School of Medicine, Hirosaki University Graduate School of Medicine, Gifu International Institute of Biotechnology, Tokyo Metropolitan Institute of Gerontology, and the participating hospitals. Written informed consent was obtained from each participant.

Selection of polymorphisms. With the use of public databases, including PubMed (NCBI) and Online Mendelian Inheritance in Man (OMIM), we selected 202 candidate genes that have been characterized and suggested to be associated with CKD. On the basis of published studies or by searching PubMed and single nucleotide polymorphism (SNP) databases [dbSNP (NCBI) and Japanese SNP database (JSNP)], we further selected 296 polymorphisms of these genes, most located in the promoter region or exons, that might be expected to result in changes in the function or expression of the encoded protein (data not shown).

Genotyping of polymorphisms. Venous blood $(7 \mathrm{ml})$ was collected in tubes containing $50 \mathrm{mmol} / \mathrm{l}$ ethylenediaminetetraacetic acid (disodium salt), and genomic DNA was isolated with a kit (Genomix; Talent, Trieste, Italy). Genotypes of the 296 polymorphisms were determined at G\&G Science (Fukushima, Japan) by a method that combines the polymerase chain reaction (PCR) and sequence-specific oligonucleotide probes with suspension array technology (Luminex, Austin, TX). Detailed genotyping methodology was described previously (17).

Statistical analysis. Quantitative data were compared between subjects with CKD and controls using the unpaired Student's t-test. Categorical data were compared with the Chi-square test. Allele frequencies were estimated using the gene counting method. In the initial screen, the genotype distributions ( $3 \times 2)$ or allele frequencies $(2 \times 2)$ of each polymorphism were compared between subjects with CKD and the controls with the Chi-square test. Polymorphisms related (P-value for allele frequency $<0.05$ ) to CKD were further examined by multivariable logistic regression analysis with adjustment for covariates, with CKD as a dependent variable and independent variables including age, gender ( 0 , woman; 1 , man), body mass index (BMI), smoking status $(0$, nonsmoker; 1 , smoker), serum concentrations of TG or HDL- or LDLcholesterol, history of hypertension or diabetes mellitus $(0$, no history; 1 , positive history), and genotype of each polymorphism; the P-value, odds ratio and $95 \%$ confidence interval were calculated. Each genotype was assessed according to dominant, recessive, and additive genetic models. Additive models included the additive 1 model 
Table I. Characteristics of subjects with low or high serum concentrations of triglycerides (TG).

\begin{tabular}{|c|c|c|c|c|c|c|}
\hline \multirow[b]{2}{*}{ Characteristic } & \multicolumn{3}{|c|}{ Low serum TG } & \multicolumn{3}{|c|}{ High serum TG } \\
\hline & CKD & Controls & P-value & CKD & Controls & P-value \\
\hline No. of subjects & 1073 & 2873 & & 633 & 1365 & \\
\hline Age (years) & $70.5 \pm 8.9$ & $66.3 \pm 9.5$ & $<0.0001$ & $69.9 \pm 8.7$ & $65.3 \pm 9.4$ & $<0.0001$ \\
\hline Gender (female/male, \%) & $40.3 / 59.7$ & $47.4 / 52.6$ & $<0.0001$ & $37.0 / 63.0$ & $38.9 / 61.1$ & 0.4074 \\
\hline Body mass index $\left(\mathrm{kg} / \mathrm{m}^{2}\right)$ & $23.0 \pm 3.4$ & $23.0 \pm 3.2$ & 0.7731 & $24.2 \pm 3.2$ & $24.5 \pm 6.3$ & 0.2997 \\
\hline Current or former smoker $(\%)$ & 21.1 & 25.4 & 0.0045 & 21.2 & 30.5 & $<0.0001$ \\
\hline Hypertension (\%) & 67.4 & 51.1 & $<0.0001$ & 70.5 & 61.5 & $<0.0001$ \\
\hline Diabetes mellitus (\%) & 31.2 & 21.9 & $<0.0001$ & 37.9 & 28.7 & $<0.0001$ \\
\hline Serum TG (mmol/l) & $1.11 \pm 0.32$ & $1.06 \pm 0.33$ & $<0.0001$ & $2.44 \pm 0.64$ & $2.49 \pm 0.68$ & 0.2150 \\
\hline Serum HDL-cholesterol (mmol/l) & $1.40 \pm 0.41$ & $1.49 \pm 0.41$ & $<0.0001$ & $1.21 \pm 0.35$ & $1.25 \pm 0.32$ & 0.0001 \\
\hline Serum LDL-cholesterol (mmol/l) & $3.07 \pm 0.85$ & $3.04 \pm 0.82$ & 0.1419 & $3.19 \pm 0.93$ & $3.11 \pm 0.94$ & 0.0754 \\
\hline Serum creatinine $(\mu \mathrm{mol} / \mathrm{l})$ & $108.8 \pm 111.3$ & $60.7 \pm 12.3$ & $<0.0001$ & $114.3 \pm 34.5$ & $120.6 \pm 12.3$ & $<0.0001$ \\
\hline eGFR (ml min $\left.\min ^{-1} 1.73 \mathrm{~m}^{-2}\right)$ & $49.0 \pm 10.7$ & $79.9 \pm 17.5$ & $<0.0001$ & $47.8 \pm 11.1$ & $77.0 \pm 13.8$ & $<0.0001$ \\
\hline End-stage renal disease $(\%)$ & 2.6 & 0 & $<0.0001$ & 2.5 & 0 & $<0.0001$ \\
\hline Myocardial infarction (\%) & 26.1 & 15.7 & $<0.0001$ & 29.4 & 23.7 & 0.0075 \\
\hline Ischemic stroke $(\%)$ & 14.1 & 9.3 & $<0.0001$ & 13.7 & 8.0 & $<0.0001$ \\
\hline
\end{tabular}

Quantitative data are the means \pm SD. eGFR, estimated glomerular filtration rate.

(heterozygotes versus wild-type homozygotes) and the additive 2 model (variant homozygotes versus wild-type homozygotes), which were analyzed simultaneously with a single statistical model. We also performed a stepwise forward selection procedure to examine the effects of genotypes as well as of other covariates on CKD; each genotype was examined according to a dominant or recessive model on the basis of statistical significance in the multivariable logistic regression analysis. Given the multiple comparisons of genotypes with CKD, we adopted the criterion of a P-value of $<0.005$ for significant association. For other clinical background data, a P-value $<0.05$ was considered statistically significant. Statistical significance was examined by two-sided tests performed with JMP version 6.0 software (SAS Institute, Cary, NC).

\section{Results}

Polymorphisms related to CKD in individuals with low or high serum concentrations of TG. The characteristics of the subjects with CKD and controls who had low or high serum concentrations of TG are listed in Table I. For individuals with low serum TG, age, the frequency of male subjects, the serum concentration of TG, as well as the prevalence of hypertension, diabetes mellitus, myocardial infarction, and ischemic stroke were greater, whereas the percentage of smokers and the serum concentration of HDL-cholesterol were lower in subjects with CKD than in controls. For individuals with high serum TG, age and the prevalence of hypertension, diabetes mellitus, myocardial infarction, and ischemic stroke were greater, whereas the percentage of smokers and the serum concentration of HDL-cholesterol were lower in subjects with CKD than in controls.
Comparison of allele frequencies with the Chi-square test revealed that nine and seven polymorphisms were related $(\mathrm{P}<0.05)$ to $\mathrm{CKD}$ in individuals with low or high serum concentrations of TG, respectively (Table II). Multivariable logistic regression analysis with adjustment for age, gender, BMI, smoking status, serum concentrations of HDL- and LDL-cholesterol, and the prevalence of hypertension and diabetes mellitus revealed that the $A \rightarrow G($ Lys45Glu) polymorphism of $M M P 3$ (additive 2 model), the $\mathrm{A} \rightarrow \mathrm{G}$ (Glu23Lys) polymorphism of KCNJ11 (recessive and additive 2 models), and the $125592 \mathrm{C} \rightarrow \mathrm{A}$ (Thr431 Asn) polymorphism of ROCK2 (dominant model) were significantly $(\mathrm{P}<0.005)$ associated with $\mathrm{CKD}$ in individuals with low serum TG, and that the $1429 \mathrm{C} \rightarrow \mathrm{T}$ polymorphism of GNB3 (dominant model), the $\mathrm{C} \rightarrow \mathrm{T}$ polymorphism of PTGSI (additive 2 model), the $\mathrm{C} \rightarrow \mathrm{G}(\mathrm{Gln} 27 \mathrm{Glu})$ polymorphism of $A D R B 2$ (dominant model), and the $734 \mathrm{C} \rightarrow \mathrm{T}$ (Thr254Ile) polymorphism of ACAT2 (dominant and additive 1 models) were significantly associated with CKD in individuals with high serum TG (Table III).

A stepwise forward selection procedure was performed to examine the effects of genotypes for the polymorphisms associated with CKD by multivariable logistic regression analysis as well as of age, gender, BMI, smoking status, serum concentrations of HDL- and LDL-cholesterol, and the prevalence of hypertension and diabetes mellitus on CKD (Table IV). For individuals with low serum TG, age, hypertension, serum HDL-cholesterol, diabetes mellitus, gender, the ROCK2 genotype (dominant model), smoking, and the $K C N J 11$ genotype (recessive model) were significant $(\mathrm{P}<0.005)$ and independent determinants of CKD. For individuals with high serum TG, age, diabetes mellitus, smoking, gender, ADRB2 (dominant model) and ACAT2 
Table II. Genotype distributions of polymorphisms related (allele frequency, $\mathrm{P}<0.05)$ to chronic kidney disease $(\mathrm{CKD})$ with low or high serum concentrations of triglycerides (TG) as determined by the Chi-square test.

\begin{tabular}{|c|c|c|c|c|c|c|}
\hline $\begin{array}{l}\text { Gene } \\
\text { symbol }\end{array}$ & Polymorphism & dbSNP & CKD & Controls & $\begin{array}{c}\text { P-value } \\
\text { (genotype) }\end{array}$ & $\begin{array}{c}\text { P-value } \\
\text { (allele frequency) }\end{array}$ \\
\hline
\end{tabular}

Low serum TG

MMP3

$$
\begin{gathered}
\mathrm{A} \rightarrow \mathrm{G}(\text { Lys45Glu) } \\
A A \\
A G \\
\mathrm{GG} \\
\mathrm{A} \rightarrow \mathrm{G}(\mathrm{Glu} 23 \text { Lys }) \\
A A \\
A G \\
G G
\end{gathered}
$$

KCNJ11

APOE

$$
\begin{gathered}
-219 \mathrm{G} \rightarrow \mathrm{T} \\
G G \\
G T \\
T T
\end{gathered}
$$

TNFRSFBB

$$
\begin{gathered}
\mathrm{C} \rightarrow \mathrm{T}(\text { Pro251Leu }) \\
C C \\
C T \\
T T \\
-1171 / 5 \mathrm{~A} \rightarrow 6 \mathrm{~A} \\
5 A 6 A \\
5 A 6 A \\
6 A 6 A
\end{gathered}
$$

$M M P 3$

ROCK2 $125592 \mathrm{C} \rightarrow \mathrm{A}(\mathrm{Thr} 431 \mathrm{Asn}) \quad$ rs10011540

$$
C C
$$$$
C A
$$$$
A A
$$

UCP1

$$
\begin{gathered}
-112 \mathrm{~A} \rightarrow \mathrm{C} \\
A A \\
A C \\
C C
\end{gathered}
$$

ZNF627

$$
\mathrm{A} \rightarrow \mathrm{G} \quad \text { rs4804611 }
$$

$A A$

$A G$

$G G$

$T H B D$

$2136 \mathrm{C} \rightarrow \mathrm{T}($ Ala455Val $)$
CC
CT
TT

High serum TG

$\begin{array}{ccc}A B C A 1 & -477 \mathrm{C} \rightarrow \mathrm{T} & \mathrm{rs} 2422493 \\ & C C & \\ & C T & \\ & T T & \\ \text { GNB3 } & 1429 \mathrm{C} \rightarrow \mathrm{T} & \mathrm{rs} 5446 \\ & C C & \\ & C T & \\ & T T & \mathrm{rs} 883484 \\ \text { PTGS1 } & \mathrm{C} \rightarrow \mathrm{T} & \\ & C C & \\ & C T & \end{array}$

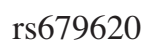

0.0005

0.0033

0.0071

0.0074

0.0076

0.0135

0.0209

$0.0475<0.0001$

0.0056

0.0012

0.0138

0.0036 
Table II. Continued.

\begin{tabular}{|c|c|c|c|c|c|c|}
\hline $\begin{array}{l}\text { Gene } \\
\text { symbol }\end{array}$ & Polymorphism & $\mathrm{dbSNP}$ & CKD & Controls & $\begin{array}{c}\text { P-value } \\
\text { (genotype) }\end{array}$ & $\begin{array}{c}\text { P-value } \\
\text { (allele frequency) }\end{array}$ \\
\hline$A D R B 2$ & $\begin{array}{c}\mathrm{C} \rightarrow \mathrm{G}(\mathrm{Gln} 27 \mathrm{Glu}) \\
C C \\
C G \\
G G\end{array}$ & rs1042714 & $\begin{array}{rr}572 & (90.4) \\
61 & (9.6) \\
0 & (0.0)\end{array}$ & $\begin{array}{r}1175(86.1) \\
185(13.5) \\
5 \quad(0.4)\end{array}$ & 0.0057 & 0.0042 \\
\hline$W R N$ & $\begin{array}{c}\mathrm{T} \rightarrow \mathrm{C}(\mathrm{Cys} 1367 \mathrm{Arg}) \\
T T \\
T C \\
C C\end{array}$ & rs1346044 & $\begin{array}{r}550(86.9) \\
80(12.6) \\
3 \quad(0.5)\end{array}$ & $\begin{array}{r}1123(82.3) \\
229(16.8) \\
13(0.9)\end{array}$ & 0.0245 & 0.0063 \\
\hline$C O M T$ & $\begin{array}{c}\mathrm{G} \rightarrow \mathrm{A}(\text { Val158Met }) \\
G G \\
G A \\
A A\end{array}$ & rs4680 & $\begin{array}{r}251(39.6) \\
303(47.9) \\
79(12.5)\end{array}$ & $\begin{array}{l}630(46.2) \\
594(43.5) \\
141(10.3)\end{array}$ & 0.0202 & 0.0072 \\
\hline ACAT2 & $\begin{array}{c}734 \mathrm{C} \rightarrow \mathrm{T}(\mathrm{Thr} 254 \mathrm{Ile}) \\
C C \\
C T \\
T T\end{array}$ & rs2272296 & $\begin{array}{r}261(41.2) \\
275(43.5) \\
97(15.3)\end{array}$ & $\begin{array}{l}474(34.8) \\
679(49.8) \\
211(15.4)\end{array}$ & 0.0140 & 0.0456 \\
\hline
\end{tabular}

genotypes (dominant model) were significant and independent determinants of CKD.

Polymorphisms related to CKD in individuals with low or high serum concentrations of HDL-cholesterol. The characteristics of the subjects with CKD and controls who had low or high serum concentrations of HDL-cholesterol are listed in Table V. For individuals with low serum HDL-cholesterol, age and the prevalence of hypertension were greater, whereas BMI and the percentage of smokers were lower in subjects with CKD than in controls. For individuals with high serum HDLcholesterol, age, the frequency of male subjects, and the serum concentrations of TG and LDL-cholesterol, as well as the prevalence of hypertension, diabetes mellitus, myocardial infarction, and ischemic stroke were greater, whereas the percentage of smokers and the serum concentration of HDLcholesterol were lower in subjects with CKD than in controls.

Comparison of allele frequencies with the Chi-square test revealed that seven and five polymorphisms were related $(\mathrm{P}<0.05)$ to $\mathrm{CKD}$ in individuals with low or high serum concentrations of HDL-cholesterol, respectively (Table VI). Multivariable logistic regression analysis with adjustment for age, gender, BMI, smoking status, serum concentrations of TG and LDL-cholesterol, and the prevalence of hypertension and diabetes mellitus revealed that the $34 \mathrm{C} \rightarrow \mathrm{G}$ (Pro12Ala) polymorphism of PPARG (additive 1 model) and the $-1607 /$ $1 \mathrm{G} \rightarrow 2 \mathrm{G}$ polymorphism of $M M P 1$ (recessive model) were significantly $(\mathrm{P}<0.005)$ associated with $\mathrm{CKD}$ in individuals with low serum HDL-cholesterol, and that the $-519 \mathrm{~A} \rightarrow \mathrm{G}$ polymorphism of MMP1 (additive 2 model) was significantly associated with CKD in individuals with high serum HDLcholesterol (Table VII).

A stepwise forward selection procedure was performed to examine the effects of genotypes for the polymorphisms associated with CKD by multivariable logistic regression analysis as well as of age, gender, BMI, smoking status, serum concentrations of TG and LDL-cholesterol, and the prevalence of hypertension and diabetes mellitus on CKD (Table VIII). For individuals with low serum HDL-cholesterol, age, hypertension, and the $M M P 1$ genotype (recessive model) were significant $(\mathrm{P}<0.005)$ and independent determinants of CKD. For individuals with high serum HDL-cholesterol, age, hypertension, diabetes mellitus, gender, and smoking were significant and independent determinants of CKD.

Polymorphisms related to CKD in individuals with low or high serum concentrations of $L D L$-cholesterol. The characteristics of the subjects with CKD and controls who had low or high serum concentrations of LDL-cholesterol are listed in Table IX. For individuals with low or high serum LDL-cholesterol, age, the frequency of male subjects, the serum concentration of TG, as well as the prevalence of hypertension, diabetes mellitus, myocardial infarction, and ischemic stroke were greater, whereas the percentage of smokers and the serum concentration of HDL-cholesterol were lower in subjects with CKD than in controls.

Comparison of allele frequencies with the Chi-square test revealed that different sets of four polymorphisms were related $(\mathrm{P}<0.05)$ to $\mathrm{CKD}$ in individuals with low or high serum concentrations of LDL-cholesterol (Table X). Multivariable logistic regression analysis with adjustment for age, gender, BMI, smoking status, serum concentrations of TG and HDLcholesterol, and the prevalence of hypertension and diabetes mellitus revealed that the $\mathrm{G} \rightarrow \mathrm{A}$ (Val158Met) polymorphism of COMT (dominant and additive 1 models) and the $\mathrm{A} \rightarrow \mathrm{G}$ (Lys45Glu) polymorphism of MMP3 (additive 2 model) were significantly $(\mathrm{P}<0.005)$ associated with $C K D$ in individuals with low serum LDL-cholesterol, and that the $584 \mathrm{G} \rightarrow \mathrm{A}$ 


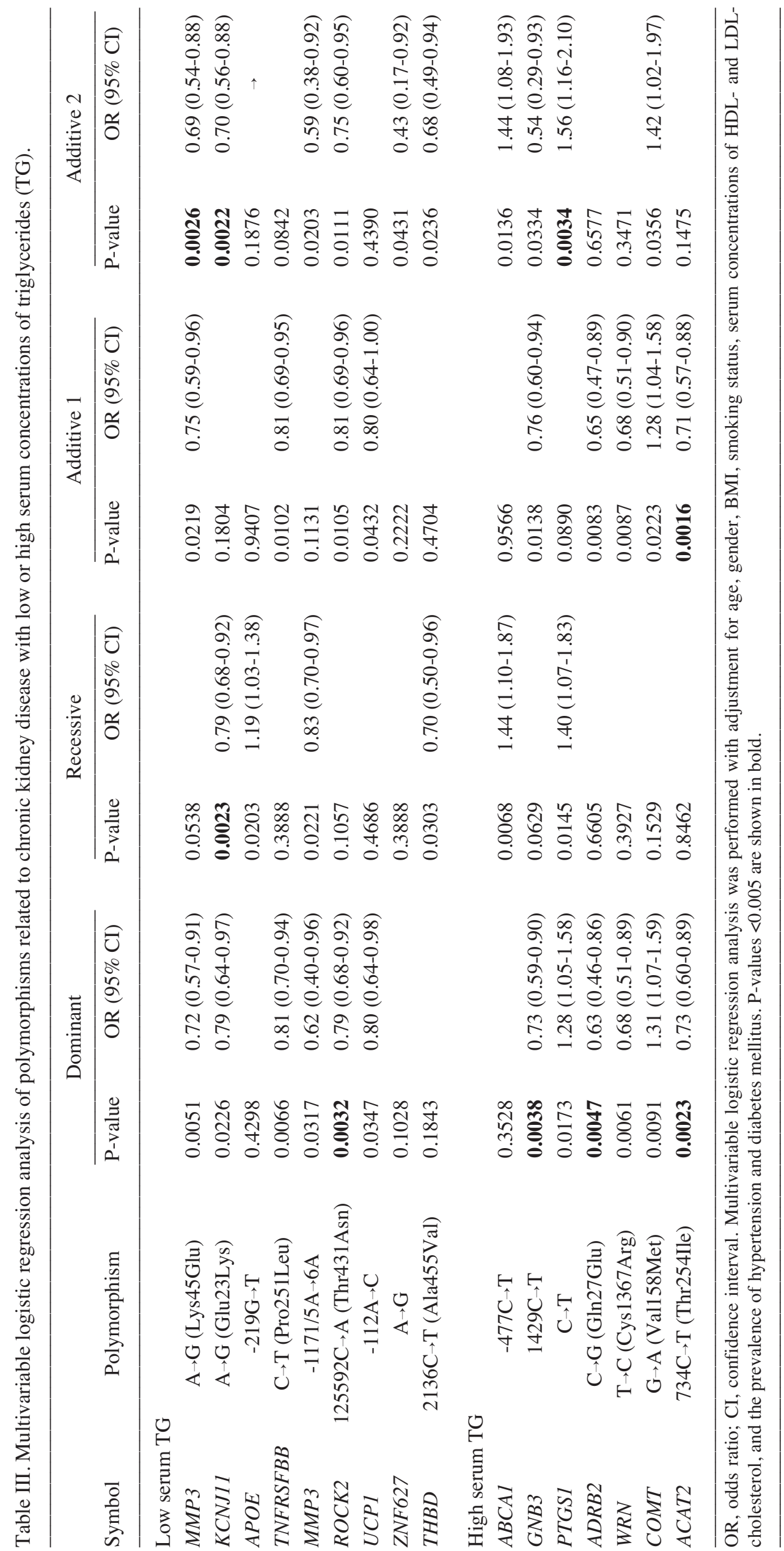


Table IV. Effects of genotypes and other characteristics on the prevalence of chronic kidney disease with low or high serum concentrations of triglycerides (TG) as determined by a stepwise forward selection procedure.

\begin{tabular}{lcc}
\hline Variable & P-value & $\mathrm{R}^{2}$ \\
\hline Low serum TG & & \\
Age & $<0.0001$ & 0.0530 \\
Hypertension & $<0.0001$ & 0.0114 \\
Serum HDL-cholesterol & $<0.0001$ & 0.0047 \\
Diabetes mellitus & 0.0002 & 0.0030 \\
Gender & 0.0013 & 0.0023 \\
ROCK2 $(A A+C A$ versus $C C)$ & 0.0020 & 0.0022 \\
Smoking & 0.0042 & 0.0018 \\
KCNJ11 $(G G$ versus $A A+A G)$ & 0.0045 & 0.0017 \\
High serum TG & & \\
Age & $<0.0001$ & 0.0429 \\
Diabetes mellitus & $<0.0001$ & 0.0090 \\
Smoking & 0.0005 & 0.0048 \\
Gender & 0.0013 & 0.0042 \\
$A D R B 2(G G+C G$ versus $C C)$ & 0.0022 & 0.0037 \\
$A C A T 2(T T+C T$ versus $C C)$ & 0.0024 & 0.0037 \\
\hline
\end{tabular}

$\mathrm{R}^{2}$, contribution rate.

(Gln192Arg) polymorphism of PON1 (dominant model) and the $2583 \mathrm{~A} \rightarrow \mathrm{G}$ (Ile $823 \mathrm{Met}$ ) polymorphism of $A B C A 1$ (additive 2 model) were significantly associated with CKD in individuals with high serum LDL-cholesterol (Table XI).
A stepwise forward selection procedure was performed to examine the effects of genotypes for the polymorphisms associated with CKD by multivariable logistic regression analysis as well as of age, gender, BMI, smoking status, serum concentrations of TG and HDL-cholesterol, and the prevalence of hypertension and diabetes mellitus on CKD (Table XII). For individuals with low serum LDL-cholesterol, age, hypertension, diabetes mellitus, serum HDL-cholesterol, smoking, gender, and the COMT genotype (dominant model) were significant $(\mathrm{P}<0.005)$ and independent determinants of CKD. For individuals with high serum LDL-cholesterol, age, serum HDL-cholesterol, the PON1 genotype (dominant model), and smoking were significant and independent determinants of CKD.

\section{Discussion}

We examined the possible relations of 296 polymorphisms of 202 candidate genes to the prevalence of CKD in individuals with low or high serum concentrations of TG or HDL- or LDL-cholesterol, given that interactions between gene polymorphisms and lipid profiles may be important in the development of CKD. Our association study with three steps of analysis (Chi-square test, multivariable logistic regression analysis, and stepwise forward selection procedure) revealed that seven different polymorphisms were significantly associated with the prevalence of CKD in individuals with different lipid profiles.

Rho-associated, coiled-coil containing protein kinase (ROCK) 1 and 2 are immediate downstream targets of a small GTP-binding protein RhoA (18). The ROCKs affect several cellular functions, one of which is cellular contraction, by controlling actin cytoskeletal assembly (19). The Asn allele of the $125592 \mathrm{C} \rightarrow \mathrm{A}$ (Thr431Asn) polymorphism of

Table V. Characteristics of subjects with low or high serum concentrations of HDL-cholesterol.

\begin{tabular}{|c|c|c|c|c|c|c|}
\hline \multirow[b]{2}{*}{ Characteristic } & \multicolumn{3}{|c|}{ Low serum HDL-cholesterol } & \multicolumn{3}{|c|}{ High serum HDL-cholesterol } \\
\hline & CKD & Controls & P-value & CKD & Controls & P-value \\
\hline No. of subjects & 374 & 649 & & 1332 & 3589 & \\
\hline Age (years) & $70.4 \pm 9.2$ & $64.8 \pm 10.4$ & $<0.0001$ & $71.1 \pm 8.7$ & $65.9 \pm 10.2$ & $<0.0001$ \\
\hline Gender (female/male, \%) & $23.0 / 77.0$ & $20.3 / 79.7$ & 0.3196 & $43.5 / 56.5$ & $49.1 / 50.9$ & 0.0005 \\
\hline Body mass index $\left(\mathrm{kg} / \mathrm{m}^{2}\right)$ & $23.8 \pm 3.3$ & $24.3 \pm 3.1$ & 0.0032 & $23.4 \pm 3.4$ & $23.4 \pm 4.7$ & 0.5825 \\
\hline Current or former smoker $(\%)$ & 22.7 & 37.4 & $<0.0001$ & 20.7 & 25.1 & 0.0009 \\
\hline Hypertension (\%) & 74.3 & 62.4 & $<0.0001$ & 66.9 & 53.0 & $<0.0001$ \\
\hline Diabetes mellitus (\%) & 42.8 & 36.7 & 0.0541 & 31.2 & 21.8 & $<0.0001$ \\
\hline Serum TG $(\mathrm{mmol} / \mathrm{l})$ & $1.89 \pm 0.87$ & $1.86 \pm 0.92$ & 0.3634 & $1.52 \pm 0.75$ & $1.46 \pm 0.78$ & 0.0001 \\
\hline Serum HDL-cholesterol (mmol/l) & $0.88 \pm 0.11$ & $0.88 \pm 0.11$ & 0.9646 & $1.46 \pm 0.36$ & $1.51 \pm 0.35$ & $<0.0001$ \\
\hline Serum LDL-cholesterol (mmol/l) & $3.07 \pm 0.86$ & $3.02 \pm 0.87$ & 0.1361 & $3.13 \pm 0.89$ & $3.07 \pm 0.86$ & 0.0362 \\
\hline Serum creatinine $(\mu \mathrm{mol} / \mathrm{l})$ & $125.1 \pm 144.5$ & $65.5 \pm 12.8$ & $<0.0001$ & $106.8 \pm 104.7$ & $61.1 \pm 12.2$ & $<0.0001$ \\
\hline eGFR (ml min $\left.{ }^{-1} 1.73 \mathrm{~m}^{-2}\right)$ & $46.9 \pm 11.8$ & $80.2 \pm 17.0$ & $<0.0001$ & $49.0 \pm 10.5$ & $78.7 \pm 16.3$ & $<0.0001$ \\
\hline End-stage renal disease $(\%)$ & 3.7 & 0 & $<0.0001$ & 2.3 & 0 & $<0.0001$ \\
\hline Myocardial infarction (\%) & 39.6 & 36.8 & 0.3836 & 23.9 & 15.0 & $<0.0001$ \\
\hline Ischemic stroke $(\%)$ & 14.7 & 16.6 & 0.4132 & 13.7 & 7.5 & $<0.0001$ \\
\hline
\end{tabular}

Quantitative data are the means \pm SD. eGFR, estimated glomerular filtration rate. 
Table VI. Genotype distributions of polymorphisms related (allele frequency, $\mathrm{P}<0.05$ ) to chronic kidney disease $(\mathrm{CKD})$ with low or high serum concentrations of HDL-cholesterol as determined by the Chi-square test.

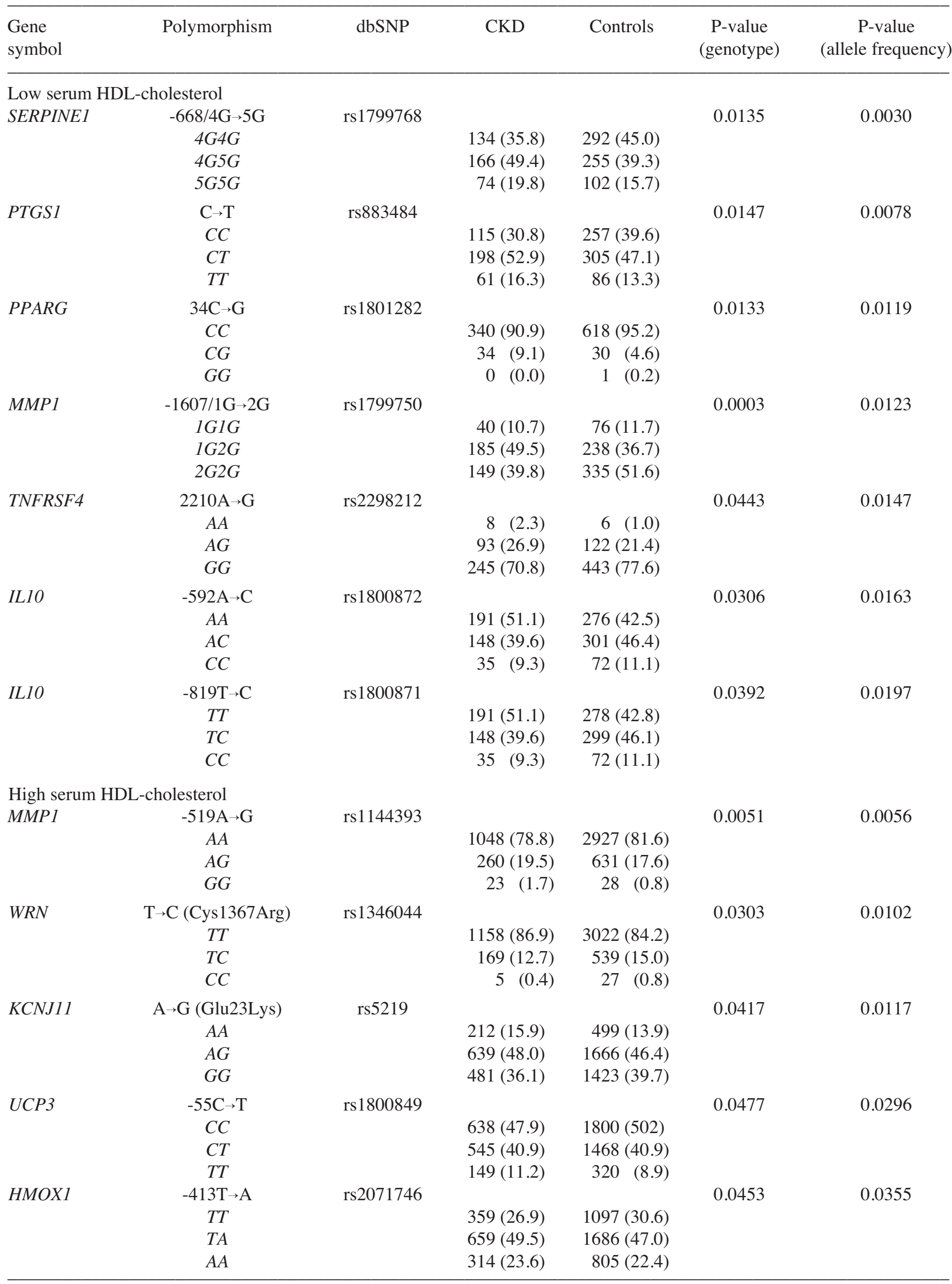




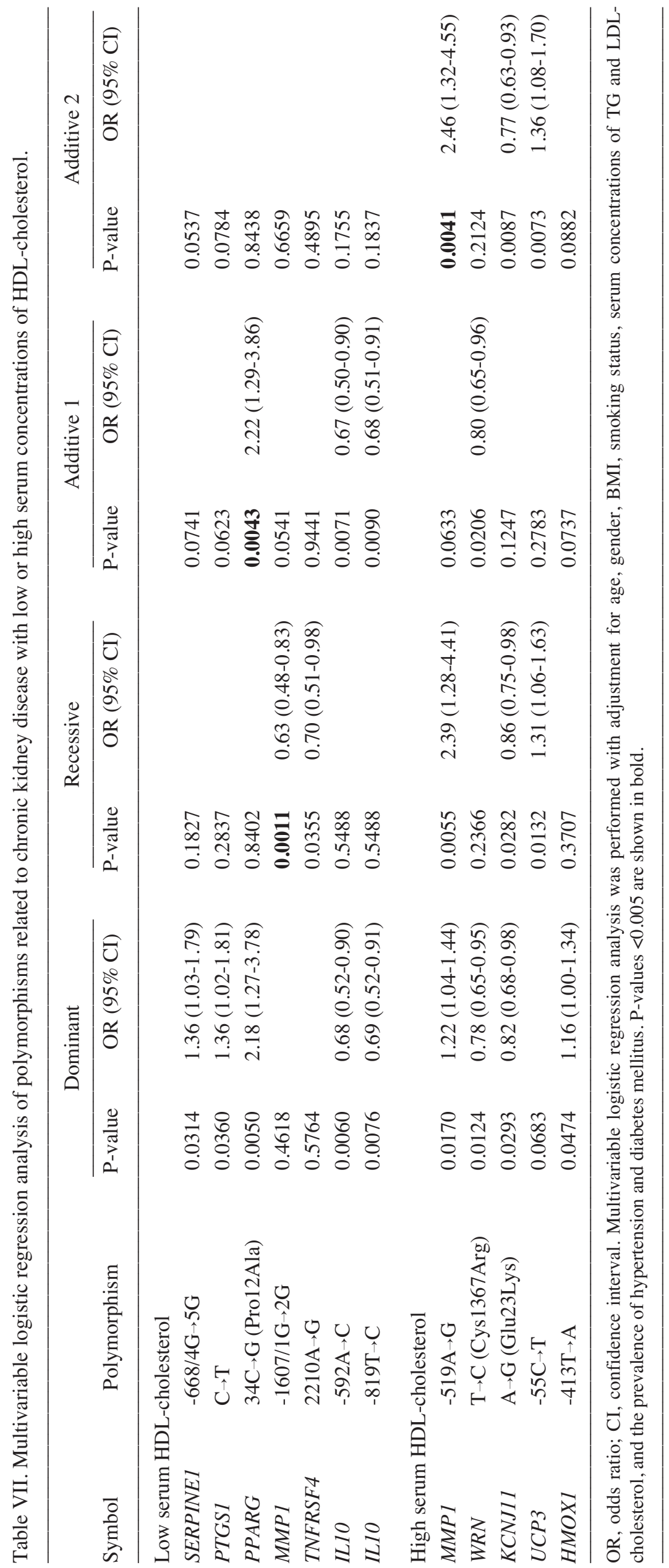


Table VIII. Effects of genotypes and other characteristics on the prevalence of chronic kidney disease with low or high serum concentrations of HDL-cholesterol as determined by a stepwise forward selection procedure.

\begin{tabular}{lrc}
\hline Variable & P-value & $\mathrm{R}^{2}$ \\
\hline Low serum HDL-cholesterol & & \\
Age & $<0.0001$ & 0.0566 \\
Hypertension & 0.0001 & 0.0122 \\
MMPl $(2 G 2 G$ versus $1 G 1 G+1 G 2 G)$ & 0.0043 & 0.0070 \\
High serum HDL-cholesterol & & \\
Age & $<0.0001$ & 0.0494 \\
Hypertension & $<0.0001$ & 0.0087 \\
Diabetes mellitus & $<0.0001$ & 0.0047 \\
Gender & $<0.0001$ & 0.0031 \\
Smoking & 0.0009 & 0.0020 \\
\hline
\end{tabular}

$\mathrm{R}^{2}$, contribution rate.

ROCK2 was associated with greater systolic and diastolic blood pressure and systemic vascular resistance (20). We showed that the $125592 \mathrm{C} \rightarrow \mathrm{A}$ (Thr431Asn) polymorphism of ROCK2 was significantly associated with CKD in individuals with a low serum concentration of TG, with the $A$ allele being protective against this condition. Although hypertension has been considered to be a risk factor for newly onset and developing CKD (6), the mechanism of the relation of the ROCK2 polymorphism to CKD remains to be elucidated.

Potassium inwardly-rectifying channel, subfamily $\mathrm{J}$, member $11(\mathrm{KCNJ} 11)$ is expressed in pancreatic $\beta$-cells and also in some other tissues, such as skeletal muscle, heart, peripheral nerve, and brain (21). Almost half of the patients diagnosed with diabetes mellitus before six months of age have a mutation in KCNJ11 (22). The Lys allele of the Glu23Lys polymorphism of KCNJ11 was shown to be related to an increased risk for type 2 diabetes mellitus in Caucasians (23). We showed that the $\mathrm{A} \rightarrow \mathrm{G}$ (Glu23Lys) polymorphism of $K C N J 11$ was significantly associated with CKD in individuals with a low serum concentration of TG, with the $G$ allele being protective against this condition, although the mechanism responsible for the association of the $G$ variant with CKD remains unclear.

Adrenergic, B-2, receptor, surface (ADRB2) plays an important role in regulating cardiac and vascular functions (24). The Glu variant of the $\mathrm{C} \rightarrow \mathrm{G}$ (Gln27Glu) polymorphism of $A D R B 2$ was shown to be related to lower blood pressure in a Japanese population (25). We showed that the $\mathrm{C} \rightarrow \mathrm{G}$ (Gln27Glu) polymorphism of $A D R B 2$ was significantly associated with CKD in individuals with a high serum concentration of TG, with the $G$ allele being protective against this condition. Effects of this polymorphism on the regulation of blood pressure may account for its association with CKD.

Acetyl-Coenzyme A acetyltransferase 2 (ACAT2) is an intracellular cholesterol esterification enzyme and uses cholesterol and fatty acid as its enzymatic substrates (26). ACAT2 is mainly found in the liver and intestine (27), the sites where apolipoprotein B-containing lipoproteins are secreted (28). The Ile allele of the $734 \mathrm{C} \rightarrow \mathrm{T}$ (Thr254Ile) polymorphism of ACAT2 was shown to be related to an increased risk for coronary heart disease in a Chinese population (26). We showed that the $734 \mathrm{C} \rightarrow \mathrm{T}$ (Thr254Ile) polymorphism of $A C A T 2$ was significantly associated with CKD in individuals with a high serum concentration of TG, with the $T$ allele being protective against this condition, although the mechanism

Table IX. Characteristics of subjects with low or high serum concentrations of LDL-cholesterol.

\begin{tabular}{|c|c|c|c|c|c|c|}
\hline \multirow[b]{2}{*}{ Characteristic } & \multicolumn{3}{|c|}{ Low serum LDL-cholesterol } & \multicolumn{3}{|c|}{ High serum LDL-cholesterol } \\
\hline & CKD & Controls & P-value & CKD & Controls & $\mathrm{P}$-value \\
\hline No. of subjects & 1263 & 3272 & & 443 & 966 & \\
\hline Age (years) & $71.3 \pm 8.7$ & $66.1 \pm 10.3$ & $<0.0001$ & $70.0 \pm 9.0$ & $64.6 \pm 9.9$ & $<0.0001$ \\
\hline Gender (female/male, \%) & $36.6 / 63.4$ & $42.2 / 57.8$ & 0.0005 & $46.1 / 53.9$ & $53.0 / 47.0$ & 0.0153 \\
\hline Body mass index $\left(\mathrm{kg} / \mathrm{m}^{2}\right)$ & $23.4 \pm 3.3$ & $23.4 \pm 4.8$ & 0.8969 & $23.7 \pm 3.5$ & $23.7 \pm 3.2$ & 0.7639 \\
\hline Current or former smoker $(\%)$ & 22.8 & 28.4 & 0.0001 & 16.3 & 22.5 & 0.0064 \\
\hline Hypertension (\%) & 68.6 & 53.6 & $<0.0001$ & 68.4 & 57.3 & $<0.0001$ \\
\hline Diabetes mellitus (\%) & 33.8 & 22.9 & $<0.0001$ & 33.4 & 28.2 & 0.0467 \\
\hline Serum TG (mmol/l) & $1.60 \pm 0.82$ & $1.50 \pm 0.83$ & $<0.0001$ & $1.62 \pm 0.70$ & $1.58 \pm 0.76$ & 0.0431 \\
\hline Serum HDL-cholesterol (mmol/l) & $1.34 \pm 0.41$ & $1.42 \pm 0.41$ & $<0.0001$ & $1.32 \pm 0.39$ & $1.38 \pm 0.36$ & 0.0002 \\
\hline Serum LDL-cholesterol (mmol/l) & $2.72 \pm 0.58$ & $2.72 \pm 0.56$ & 0.4699 & $4.23 \pm 0.61$ & $4.22 \pm 0.64$ & 0.7629 \\
\hline Serum creatinine $(\mu \mathrm{mol} / \mathrm{l})$ & $111.2 \pm 112.7$ & $62.1 \pm 12.2$ & $<0.0001$ & $109.8 \pm 120.6$ & $60.5 \pm 12.7$ & $<0.0001$ \\
\hline eGFR (ml min $\left.{ }^{-1} 1.73 \mathrm{~m}^{-2}\right)$ & $48.4 \pm 11.0$ & $78.9 \pm 15.9$ & $<0.0001$ & $49.0 \pm 10.5$ & $79.4 \pm 18.1$ & $<0.0001$ \\
\hline End-stage renal disease $(\%)$ & 2.5 & 0.0 & $<0.0001$ & 2.7 & 0.0 & $<0.0001$ \\
\hline Myocardial infarction (\%) & 25.8 & 16.9 & $<0.0001$ & 31.6 & 23.0 & 0.0007 \\
\hline Ischemic stroke (\%) & 13.6 & 8.9 & $<0.0001$ & 14.9 & 8.8 & 0.0008 \\
\hline
\end{tabular}

Quantitative data are the means \pm SD. eGFR, estimated glomerular filtration rate. 
Table X. Genotype distributions of polymorphisms related (allele frequency, $\mathrm{P}<0.05$ ) to chronic kidney disease $(\mathrm{CKD})$ with low or high serum concentrations of LDL-cholesterol as determined by the Chi-square test.

\begin{tabular}{|c|c|c|c|c|c|c|}
\hline $\begin{array}{l}\text { Gene } \\
\text { symbol }\end{array}$ & Polymorphism & dbSNP & CKD & Controls & $\begin{array}{c}\text { P-value } \\
\text { (genotype) }\end{array}$ & $\begin{array}{c}\text { P-value } \\
\text { (allele frequency) }\end{array}$ \\
\hline \multicolumn{7}{|c|}{ Low serum LDL-cholesterol } \\
\hline \multirow[t]{4}{*}{ COMT } & $\mathrm{G} \rightarrow \mathrm{A}($ Val158Met $)$ & rs679620 & & & 0.0059 & $<0.0001$ \\
\hline & $G G$ & & $507(40.1)$ & $1481 \quad(45.3)$ & & \\
\hline & $G A$ & & $620(49.1)$ & $1447(442.0)$ & & \\
\hline & $A A$ & & $136(10.8)$ & $343(10.5)$ & & \\
\hline \multirow[t]{4}{*}{$M M P 3$} & $\mathrm{~A} \rightarrow \mathrm{G}($ Lys45Glu) & rs679620 & & & 0.0380 & 0.0105 \\
\hline & $A A$ & & $150(11.9)$ & $326(10.0)$ & & \\
\hline & $A G$ & & $568(45.0)$ & $1412(43.2)$ & & \\
\hline & $G G$ & & $545(43.1)$ & $1533(46.8)$ & & \\
\hline \multirow[t]{4}{*}{$M M P 1$} & $-1607 / 1 \mathrm{G} \rightarrow 2 \mathrm{G}$ & rs1799750 & & & 0.0334 & 0.0226 \\
\hline & $1 G 1 G$ & & $149(11.8)$ & $361(11.0)$ & & \\
\hline & $1 G 2 G$ & & $587(46.5)$ & $1405(43.0)$ & & \\
\hline & $2 G 2 G$ & & $527(41.7)$ & $1505(46.0)$ & & \\
\hline \multirow[t]{4}{*}{ ALOX5 } & $\mathrm{G} \rightarrow \mathrm{A}($ Glu254Lys $)$ & rs2228065 & & & 0.0160 & 0.0235 \\
\hline & $G G$ & & $1216(96.3)$ & $3187(97.4)$ & & \\
\hline & $G A$ & & $45 \quad(3.6)$ & 84 (2.6) & & \\
\hline & $A A$ & & $2(0.1)$ & $0 \quad(0.0)$ & & \\
\hline \multicolumn{7}{|c|}{ High serum LDL-cholesterol } \\
\hline \multirow[t]{4}{*}{$W R N$} & $\mathrm{~T} \rightarrow \mathrm{C}(\mathrm{Cys} 1367 \mathrm{Arg})$ & rs1346044 & & & 0.0384 & 0.0098 \\
\hline & $T T$ & & $400(90.3)$ & $826(85.5)$ & & \\
\hline & $T C$ & & $41 \quad(9.3)$ & $132(13.7)$ & & \\
\hline & $C C$ & & $2(0.4)$ & $8 \quad(0.8)$ & & \\
\hline \multirow[t]{4}{*}{ PON1 } & $584 \mathrm{G} \rightarrow \mathrm{A}(\mathrm{Gln} 192 \mathrm{Arg})$ & rs662 & & & 0.0091 & 0.0102 \\
\hline & $G G$ & & $409(42.3)$ & $409(42.3)$ & & \\
\hline & $G A$ & & $444(46.0)$ & $444(46.0)$ & & \\
\hline & $A A$ & & $113(11.7)$ & $113(11.7)$ & & \\
\hline \multirow[t]{4}{*}{$A B C A 1$} & $2583 \mathrm{~A} \rightarrow \mathrm{G}(\mathrm{Ile} 823 \mathrm{Met})$ & rs4149313 & & & 0.0313 & 0.0124 \\
\hline & $A A$ & & $73(16.5)$ & $113(11.7)$ & & \\
\hline & $A G$ & & $204(46.0)$ & $442(45.8)$ & & \\
\hline & $G G$ & & $166(37.5)$ & $410(42.5)$ & & \\
\hline \multirow[t]{4}{*}{ NOS3 } & $-786 \mathrm{~T} \rightarrow \mathrm{C}$ & rs2070744 & & & 0.0182 & 0.0298 \\
\hline & $T T$ & & $374(84.4)$ & $761(78.8)$ & & \\
\hline & $T C$ & & $64(14.5)$ & $198(20.5)$ & & \\
\hline & $C C$ & & $5(1.1)$ & $7 \quad(0.7)$ & & \\
\hline
\end{tabular}

responsible for the association of the $T$ variant with CKD remains unknown.

Matrix metallopeptidase 1 (MMP1) degrades fibrillar collagens, particularly types I and III, which are resistant to most other proteinases (29). The $2 G$ allele of the $-1607 / 1 \mathrm{G} \rightarrow 2 \mathrm{G}$ polymorphism of $M M P 1$, which is located in the promoter region of the gene, was shown to be related to increased transcriptional activity (30). In addition, the $-519 \mathrm{~A} \rightarrow \mathrm{G}$ polymorphism of $M M P 1$ was shown to be related to the risk of myocardial infarction as part of a haplotype (31) and an increased intima-media thickness of the carotid artery in a German population with hypertension (32). We showed that the $-1607 / 1 \mathrm{G} \rightarrow 2 \mathrm{G}$ polymorphism of $M M P 1$ was significantly associated with CKD in individuals with a low serum concentration of HDL-cholesterol, with the $2 G$ allele being protective against this condition. Effects of this polymorphism on the development of atherosclerosis may account for its association with CKD.

Catechol-O-methyltransferase (COMT) is involved in catechol homeostasis and plays a regulatory role (33). In addition, COMT is a key enzyme in the degradation of estrogens, which regulate several biological processes involved in the pathogenesis of myocardial infarction (34). The Met allele of the $\mathrm{G} \rightarrow \mathrm{A}$ (Val158Met) polymorphism of COMT was associated with a decreased activity of COMT (35) and was protective against myocardial infarction among 


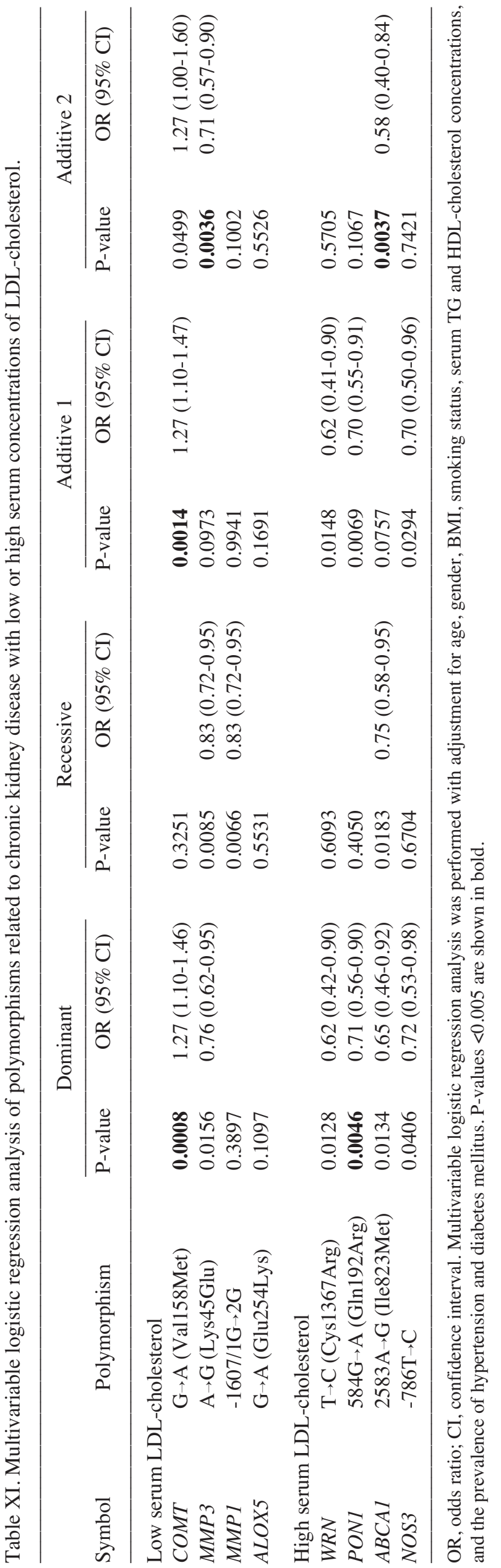

Table XII. Effects of genotypes and other characteristics on the prevalence of chronic kidney disease with low or high serum concentrations of LDL-cholesterol as determined by a stepwise forward selection procedure.

\begin{tabular}{lrc}
\hline Variable & P-value & $\mathrm{R}^{2}$ \\
\hline Low serum LDL-cholesterol & & \\
Age & $<0.0001$ & 0.0491 \\
Hypertension & $<0.0001$ & 0.0113 \\
Diabetes mellitus & $<0.0001$ & 0.0074 \\
Serum HDL-cholesterol & $<0.0001$ & 0.0036 \\
Smoking & 0.0003 & 0.0024 \\
Gender & 0.0009 & 0.0021 \\
COMT (AA+GA versus $G G)$ & 0.0011 & 0.0020 \\
High serum LDL-cholesterol & & \\
Age & $<0.0001$ & 0.0545 \\
Serum HDL-cholesterol & 0.0009 & 0.0064 \\
PONI $(A A+G A$ versus $G G)$ & 0.0028 & 0.0052 \\
Smoking & 0.0039 & 0.0048 \\
\hline
\end{tabular}

$\mathrm{R}^{2}$, contribution rate.

hypertensive patients (34). We showed that the $G \rightarrow A$ (Val158Met) polymorphism of COMT was significantly associated with CKD in individuals with a low serum concentration of LDL-cholesterol, with the $A$ allele representing a risk factor for this condition, although the mechanism responsible for the association of the $A$ variant with CKD remains to be elucidated.

Paraoxonase 1 (PON1) is one of the paraoxonase family involved in protecting LDL from lipid oxidation (36). Given that paraoxonases have antioxidant activity and that oxidized LDL is a key mediator of atherosclerosis, the paraoxonases have been considered susceptibility genes for coronary heart disease and ischemic stroke $(37,38)$. The Arg allele of the $584 \mathrm{G} \rightarrow \mathrm{A}(\mathrm{Gln} 192 \mathrm{Arg})$ polymorphism of PONI was shown to be related to an increased risk of stroke (38) and endothelial dysfunction among normotensive diabetic subjects (39). We showed that the $584 \mathrm{G} \rightarrow \mathrm{A}(\mathrm{G} \ln 192 \mathrm{Arg})$ polymorphism of PON1 was significantly associated with CKD in individuals with a high serum concentration of LDL-cholesterol, with the $A$ allele being protective against this condition. The discordant results might be attributed to the stratification of subjects by lipid profiles in the present study.

Our study has several limitations: (i) We used an estimated glomerular filtration rate (eGFR) instead of a directly measured rate to define CKD. (ii) We were not able to obtain information on the underlying renal disease of CKD in each subject with CKD. (iii) Although a previous study $(6,40)$ showed smoking to be a risk factor for CKD, the frequency of smoking was significantly lower in subjects with CKD than in controls. Selection bias could not be excluded in the present study, given that the subjects were recruited both from patients who visited the hospitals and from communitydwelling individuals. (iv) It is possible that one or more of 
the polymorphisms associated with CKD in the present study are in linkage disequilibrium with other polymorphisms in the same gene or in other nearby genes that are actually responsible for the development of this condition. (v) The functional relevance of the identified polymorphisms to gene transcription or to protein function was not determined in the present study. (vi) Although we adopted the criterion of $\mathrm{P}<0.005$ for significant association to compensate for the multiple comparisons of genotypes with CKD, it is not possible to exclude completely potential statistical errors such as false positives.

In conclusion, our present results implicate seven different polymorphisms as being associated with CKD in individuals with low or high serum concentrations of TG or HDL- or LDL-cholesterol. Determination of genotypes for these polymorphisms may prove informative for assessment of the genetic factors for CKD and may contribute to the personalized prevention of this condition. Our present study can be considered as hypothesis generating, and validation of our findings will require their replication with independent subject panels.

\section{Acknowledgements}

In addition to the authors, the following investigators participated in the study: H. Matsuo and T. Segawa (Gifu Prefectural General Medical Center); T. Hibino, K. Yajima, T. Fujimaki and T. Kawamiya (Gifu Prefectural Tajimi Hospital); A. Yasunaga, H. Park, N. Fuku, M. Tanaka, T. Suzuki and H. Yoshida (Tokyo Metropolitan Institute of Gerontology). We also thank nursing and laboratory staff of the participating hospitals. This work was supported in part by Grants-in-Aid for Scientific Research from the Ministry of Education, Culture, Sports, Science, and Technology of Japan (nos. 18209023, 18018021, and 19659149 to Y.Y.).

\section{References}

1. Weiner DE, Tighiouart H, Amin MG, et al: Chronic kidney disease as a risk factor for cardiovascular disease and all-cause mortality: a pooled analysis of community-based studies. J Am Soc Nephrol 15: 1307-1315, 2004.

2. Jafar TH, Stark PC, Schmid CH, et al: Progression of chronic kidney disease: the role of blood pressure control, proteinuria, and angiotensin-converting enzyme inhibition: a patient-level meta-analysis. Ann Intern Med 139: 244-252, 2003.

3. Iseki K, Oshiro S, Tozawa M, Ikemiya Y, Fukiyama K and Takishita S: Prevalence and correlates of diabetes mellitus in a screened cohort in Okinawa, Japan. Hypertens Res 25: 185-190, 2002.

4. Moranne O, Watier L, Rossert J, Stengel B and GN-Progress Study Group: Primary glomerulonephritis: an update on renal survival and determinants of progression. Q J Med 101: 215-224, 2008.

5. Haroun MK, Jaar BG, Hoffman SC, Comstock GW, Klag MJ and Coresh J: Risk factors for chronic kidney disease: a prospective study of 23,534 men and women in Washington County, Maryland. J Am Soc Nephrol 14: 2934-2941, 2003.

6. Yamagata K, Ishida K, Sairenchi T, et al: Risk factors for chronic kidney disease in a community-based population: a 10year follow-up study. Kidney Int 71: 159-166, 2007.

7. Muntner P, Coresh J, Smith JC, Eckfeldt J and Klag MJ: Plasma lipids and risk of developing renal dysfunction: the atherosclerosis risk in communities study. Kidney Int 58: 293-301, 2000.

8. Schaeffner ES, Kurth T, Curhan GC, et al: Cholesterol and the risk of renal dysfunction in apparently healthy men. J Am Soc Nephrol 14: 2084-2091, 2003.
9. De Jong PE and Brenner BM: From secondary to primary prevention of progressive renal disease: the case for screening for albuminuria. Kidney Int 66: 2109-2118, 2004.

10. National Kidney Foundation: K/DOQI clinical practice guidelines for chronic kidney disease: evaluation, classification, and stratification. Am J Kidney Dis 39 (2 Suppl 1): 1-266, 2002.

11. Gharavi AG, Yan Y, Scolari F, et al: IgA nephropathy, the most common cause of glomerulonephritis, is linked to 6q22-23. Nat Genet 26: 354-357, 2000.

12. Hanson RL, Craig DW and Millis MP: Identification of PVT1 as a candidate gene for end-stage renal disease in type 2 diabetes using a pooling-based genome-wide single nucleotide polymorphism association study. Diabetes 56: 975-983, 2007.

13. Doi K, Noiri E, Nakao A, Fujita T, Kobayashi S and Tokunaga K: Functional polymorphisms in the vascular endothelial growth factor gene are associated with development of end-stage renal disease in males. J Am Soc Nephrol 17: 823-830, 2006.

14. Wetmore JB, Hung AM, Lovett DH, Sen S, Quershy O and Johansen KL: Interleukin-1 gene cluster polymorphisms predict risk of ESRD. Kidney Int 68: 278-284, 2005.

15. Imai E, Matsuo S, Makino H, et al: Chronic Kidney Disease Japan Cohort (CKD-JAC) study: design and methods. Hypertens Res 31: 1101-1107, 2008

16. Go AS, Chertow GM, Fan D, McCulloch CE and Hsu CY: Chronic kidney disease and the risks of death, cardiovascular events, and hospitalization. N Engl J Med 351: 1296-1305, 2004.

17. Itoh Y, Mizuki N, Shimada T, et al: High-throughput DNA typing of HLA-A, -B, -C, and -DRB1 loci by a PCR-SSOPLuminex method in the Japanese population. Immunogenetics 57: 717-729, 2005

18. Noma K, Oyama N and Liao JK: Physiological role of ROCKs in the cardiovascular system. Am J Physiol Cell Physiol 290: C661-C668, 2006.

19. Rankinen T, Church T, Rice T, Markward N, Blair SN and Bouchard C: A major haplotype block at the rho-associated kinase 2 locus is associated with a lower risk of hypertension in a recessive manner: the HYPGENE study. Hypertens Res 31: 1651-1657, 2008.

20. Seasholtz TM, Wessel J, Rao F, et al: Rho kinase polymorphism influences blood pressure and systemic vascular resistance in human twins: role of heredity. Hypertension 47: 937-947, 2006.

21. Hattersley AT and Ashcroft FM: Activating mutations in Kir6.2 and neonatal diabetes: new clinical syndromes, new scientific insights, and new therapy. Diabetes 54: 2503-2513, 2005.

22. Gloyn AL, Pearson ER, Antcliff JF, et al: Activating mutations in the gene encoding the ATP-sensitive potassium-channel subunit Kir6.2 and permanent neonatal diabetes. N Engl J Med 350: 1838-1849, 2004

23. Hani EH, Boutin P, Durand E, et al: Missense mutations in the pancreatic islet beta cell inwardly rectifying $\mathrm{K}^{+}$channel gene (KIR6.2/BIR): a meta-analysis suggests a role in the polygenic basis of Type II diabetes mellitus in Caucasians. Diabetologia 41: 1511-1515, 1998.

24. Barbato E, Piscione F, Bartunek J, et al: Role of beta2 adrenergic receptors in human atherosclerotic coronary arteries. Circulation 111: 288-294, 2005

25. Kato N, Sugiyama T, Morita H, et al: Association analysis of beta(2)-adrenergic receptor polymorphisms with hypertension in Japanese. Hypertension 37: 286-292, 2001.

26. He X, Lu Y, Saha N, Yang H and Heng CK: Acyl-CoA: cholesterol acyltransferase-2 gene polymorphisms and their association with plasma lipids and coronary artery disease risks. Hum Genet 118: 393-403, 2005.

27. Anderson RA, Joyce C, Davis M, et al: Identification of a form of acyl-CoA:cholesterol acyltransferase specific to liver and intestine in nonhuman primates. J Biol Chem 273: 26747-26754, 1998.

28. Burnett JR, Wilcox LJ, Telford DE, et al: Inhibition of ACAT by avasimibe decreases both VLDL and LDL apolipoprotein B production in miniature pigs. J Lipid Res 40: 1317-1327, 1999.

29. Visse R and Nagase H: Matrix metalloproteinases and tissue inhibitors of metalloproteinases: structure, function, and biochemistry. Circ Res 92: 827-839, 2003.

30. Rutter JL, Mitchell TI, Butticè G, et al: A single nucleotide polymorphism in the matrix metalloproteinase-1 promoter creates an Ets binding site and augments transcription. Cancer Res 58: 5321-5325, 1998.

31. Pearce E, Tregouet DA, Samnegård A, et al: Haplotype effect of the matrix metalloproteinase- 1 gene on risk of myocardial infarction. Circ Res 97: 1070-1076, 2005. 
32. Armstrong C, Abilleira S, Sitzer M, Markus HS and Bevan S: Polymorphisms in MMP family and TIMP genes and carotid artery intima-media thickness. Stroke 38: 2895-2899, 2007.

33. Männistö PT and Kaakkola S: Catechol-O-methyltransferase (COMT): biochemistry, molecular biology, pharmacology, and clinical efficacy of the new selective COMT inhibitors. Pharmacol Rev 51: 593-628, 1999.

34. Eriksson AL, Skrtic S, Niklason A, et al: Association between the low activity genotype of catechol-O-methyltransferase and myocardial infarction in a hypertensive population. Eur Heart $\mathbf{J}$ 25: 386-391, 2004.

35. Lachman HM, Papolos DF, Saito T, Yu YM, Szumlanski CL and Weinshilboum RM: Human catechol-O-methyltransferase pharmacogenetics: description of a functional polymorphism and its potential application to neuropsychiatric disorders. Pharmacogenetics 6: 243-250, 1996.

36. Reddy ST, Wadleigh DJ, Grijalva V, et al: Human paraoxonase3 is an HDL-associated enzyme with biological activity similar to paraoxonase-1 protein but is not regulated by oxidized lipids. Arterioscler Thromb Vasc Biol 21: 542-547, 2001.
37. Wheeler JG, Keavney BD, Watkins H, Collins R and Danesh J: Four paraoxonase gene polymorphisms in 11212 cases of coronary heart disease and 12786 controls: meta-analysis of 43 studies. Lancet 363: 689-695, 2004.

38. Ranade K, Kirchgessner TG, Iakoubova OA, et al: Evaluation of the paraoxonases as candidate genes for stroke: Gln192Arg polymorphism in the paraoxonase 1 gene is associated with increased risk of stroke. Stroke 36: 2346-2350, 2005.

39. Irace C, Cortese C, Fiaschi E, et al: The influence of PON1 192 polymorphism on endothelial function in diabetic subjects with or without hypertension. Hypertens Res 31: 507-513, 2008.

40. Orth SR: Smoking and the kidney. J Am Soc Nephrol 13 : 1663-1672, 2002. 